\title{
Response Surface Methodology for Biodiesel Production Using Calcium Methoxide Catalyst Assisted with Tetrahydrofuran as Cosolvent
}

\author{
Nichaonn Chumuang ${ }^{1}$ and Vittaya Punsuvon ${ }^{1,2,3}$ \\ ${ }^{1}$ Department of Chemistry, Faculty of Science, Kasetsart University, Bangkok 10900, Thailand \\ ${ }^{2}$ Center of Excellence-Oil Palm, Kasetsart University, Bangkok 10900, Thailand \\ ${ }^{3}$ Center for Advance Studies in Tropical Natural Resource, National Research University, Kasetsart University, \\ Bangkok 10900, Thailand \\ Correspondence should be addressed to Vittaya Punsuvon; fscivit@ku.ac.th
}

Received 15 March 2017; Accepted 12 June 2017; Published 19 July 2017

Academic Editor: Raj K. Gupta

Copyright (c) 2017 Nichaonn Chumuang and Vittaya Punsuvon. This is an open access article distributed under the Creative Commons Attribution License, which permits unrestricted use, distribution, and reproduction in any medium, provided the original work is properly cited.

The present study was performed to optimize a heterogeneous calcium methoxide $\left(\mathrm{Ca}\left(\mathrm{OCH}_{3}\right)_{2}\right)$ catalyzed transesterification process assisted with tetrahydrofuran (THF) as a cosolvent for biodiesel production from waste cooking oil. Response surface methodology (RSM) with a 5-level-4-factor central composite design was applied to investigate the effect of experimental factors on the percentage of fatty acid methyl ester (FAME) conversion. A quadratic model with an analysis of variance obtained from the RSM is suggested for the prediction of FAME conversion and reveals that $99.43 \%$ of the observed variation is explained by the model. The optimum conditions obtained from the RSM were $2.83 \mathrm{wt} \%$ of catalyst concentration, 11.6: 1 methanol-to-oil molar ratio, $100.14 \mathrm{~min}$ of reaction time, and $8.65 \% \mathrm{v} / \mathrm{v}$ of THF in methanol concentration. Under these conditions, the properties of the produced biodiesel satisfied the standard requirement. THF as cosolvent successfully decreased the catalyst concentration, methanol-to-oil molar ratio, and reaction time when compared with biodiesel production without cosolvent. The results are encouraging for the application of $\mathrm{Ca}\left(\mathrm{OCH}_{3}\right)_{2}$ assisted with THF as a cosolvent for environmentally friendly and sustainable biodiesel production.

\section{Introduction}

Currently, heterogeneous catalysts have been developed for use in a transesterification reaction for biodiesel production due to the problems of homogeneous catalysts in terms of water treatment and the nonreusability of the catalyst. Although heterogeneous catalysts have many advantages [1], their disadvantages are also many such as a high oil-toalcohol molar ratio, high temperature, and a long reaction time [2]. The addition of a cosolvent such as tetrahydrofuran (THF) to the reaction medium is an alternative way to enhance the reaction rate, as well as increasing the solubility and mass transfer between the oil and methanol [3]. THF is favorable because it can dissolve organic compounds on the hydrophobic site and bind water or alcohol on the hydrophilic site [4]. In addition, THF is a nonhazardous and unreactive chemical with a low boiling point $\left(67^{\circ} \mathrm{C}\right)$, and it can be distilled with methanol and recycled at the end of the reaction process. In the previous work [5], THF was used as a cosolvent to accelerate the biodiesel production using a calcium oxide $(\mathrm{CaO})$ catalyst but no experiments have been reported on using THF as a cosolvent with $\mathrm{Ca}\left(\mathrm{OCH}_{3}\right)_{2}$ catalyst. Thus, our experiment represents the first report of such a study. Response surface methodology (RSM) has been applied to analyze research involving a complex variable process. RSM employs multiple regression and correlation analyses to assess the effects of two or more independent factor on the dependent variables. Its principal advantage is in reducing the number of experimental runs required to generate sufficient information for a statistically acceptable result. RSM has been 
successfully applied in the study and optimization of biodiesel production from various feed stocks $[6,7]$.

In this study, we select $\mathrm{Ca}\left(\mathrm{OCH}_{3}\right)_{2}$ as heterogeneous catalyst in WCO biodiesel production because $\mathrm{Ca}\left(\mathrm{OCH}_{3}\right)_{2}$ showed higher activity and very low solubility compared to $\mathrm{CaO}$ catalyst in the transesterification of rapeseed oil [8]. Calcium methoxide $\left(\mathrm{Ca}\left(\mathrm{OCH}_{3}\right)_{2}\right)$ was prepared from quick lime and its properties were analyzed using $\mathrm{X}$-ray diffraction (XRD) and attenuated total reflection Fourier transform infrared (ATR-FTIR) spectroscopy. The synthesized $\mathrm{Ca}\left(\mathrm{OCH}_{3}\right)_{2}$ was also tested as a heterogeneous catalyst assisted with THF in the transesterification of waste cooking oil (WCO). RSM was utilized for process optimization. The reusability of $\mathrm{Ca}\left(\mathrm{OCH}_{3}\right)_{2}$ in biodiesel production was also studied.

\section{Materials and Methods}

2.1. Materials. The $\mathrm{WCO}$ in this research was obtained from the Vehicle and Building Station, Kasetsart University, Bangkok, Thailand. The fatty acid composition in the WCO was $1.11 \mathrm{wt} \%$ myristic acid, $35.92 \mathrm{wt} \%$ palmitic acid, $4.65 \mathrm{wt} \%$ stearic acid, $46.02 \mathrm{wt} \%$ oleic acid, and $12.30 \mathrm{wt} \%$ linoleic acid. The calculated average molecular weight of the WCO based on the fatty acid composition was $855 \mathrm{~g} / \mathrm{mol}$ and its free fatty acid content was $0.7 \mathrm{wt} \%$. Quick lime powder was supplied by Suthagun Co., Ltd. (Thailand). Analytical grade methanol and n-heptane were purchased from Merck (Germany). Standard chromatographic grade fatty acid methyl esters (FAME) were purchased from Sigma-Aldrich (Switzerland).

2.2. Catalyst Preparation. $\mathrm{Ca}\left(\mathrm{OCH}_{3}\right)_{2}$ was prepared following the work of Suwanthai et al. [6]. Briefly, the quick lime powder was heated in a furnace at $700^{\circ} \mathrm{C}$ for $2 \mathrm{~h}$. Then, $5 \mathrm{~g}$ of calcined quick lime powder was placed in a three-necked flask with $150 \mathrm{ml}$ of methanol. The reaction of calcined quick lime and methanol was performed at $65^{\circ} \mathrm{C}$ for $2 \mathrm{~h}$ with vigorous stirring. After that, the residual $\mathrm{Ca}\left(\mathrm{OCH}_{3}\right)_{2}$ was collected by filtration and washed several times with methanol. Finally, the residual $\mathrm{Ca}\left(\mathrm{OCH}_{3}\right)_{2}$ was dried in an oven at $105^{\circ} \mathrm{C}$ for $1 \mathrm{~h}$ and kept in a desiccator until used.

2.3. Catalyst Characterization. The XRD analysis was carried out using a D8 Advance Bruker diffractometer (USA) with $\mathrm{Cu} \mathrm{k}_{\alpha}$ radiation to scan a $2 \theta$ range from $5^{\circ}$ to $40^{\circ}$. The surface functional groups of the $\mathrm{Ca}\left(\mathrm{OCH}_{3}\right)_{2}$ catalyst were determined using ATR-FTIR on a Bruker Equinox 55 FTIR spectrometer (USA).

2.4. Transesterification Process. The transesterification reactions were carried out in a three-necked flask equipped with a reflux condenser and a thermometer on a magnetic stirrer heater at $65^{\circ} \mathrm{C}$ and $750 \mathrm{rpm}$. The $\mathrm{Ca}\left(\mathrm{OCH}_{3}\right)_{2}$ was added immediately to the flask when the reactants (oil and methanol) reached the required temperature. After the reaction was complete, the products were separated using centrifugation. The top layer consisted of biodiesel and the bottom layer contained a mixture of glycerol and $\mathrm{Ca}\left(\mathrm{OCH}_{3}\right)_{2}$.

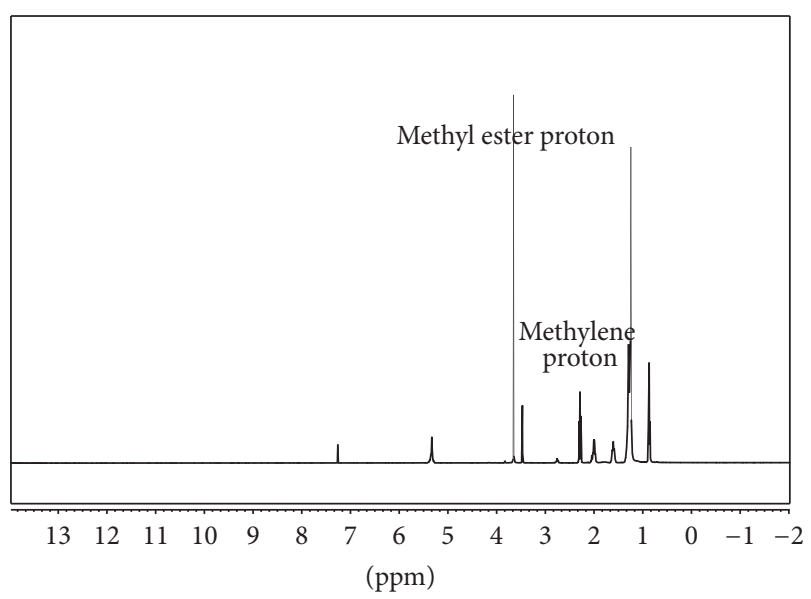

Figure 1: ${ }^{1} \mathrm{H}-\mathrm{NMR}$ spectrum of WCO biodiesel.

The excess methanol contained in the biodiesel was further removed at $105^{\circ} \mathrm{C}$ in an oven. In the obtained biodiesel the $\%$ FAME conversion was investigated using proton nuclear magnetic resonance spectroscopy ( $\left.{ }^{1} \mathrm{H}-\mathrm{NMR}\right)$ [9].

2.5. Experimental Design and Statistical Analysis. RSM based on a central composite design (CCD) of experiments was used to optimize the biodiesel production process from the WCO and to investigate the influence of different transesterification process variables on the \% FAME conversion. At five levels of independent variables ranging from -2 to $+2,30$ experimental runs were carried out with the four independent variables: methanol-to-oil-molar ratio $(A)$; catalyst concentration $(B)$; reaction time $(C)$; and cosolvent in methanol concentration $(D)$. In addition, the 30 runs included 16 factorial points, 8 axial points, and 6 replicates at the center point to determine the experimental error for this study. The obtained experimental data was analyzed using a second-order polynomial (see (1)) to find the relationship between the independent variables and the \% FAME conversion $[6,7]$.

$$
Y=b_{0}+\sum_{i=1}^{k} b_{i} x_{i}+\sum_{i=1}^{k} b_{i i} x_{i}^{2}+\sum_{i=1}^{k} \sum_{j=1}^{k} b_{i j} x_{i} x_{j},
$$

where $Y$ is the response (\% FAME conversion), $b_{0}$ is the intercept, $b_{i}, b_{i i}$, and $b_{i j}$ are the linear, quadratic, and interactive coefficients, respectively, $k$ is the number of factors, and $x_{i}$ and $x_{j}$ are the independent variables under study.

Statistical analysis of the model was performed to evaluate the analysis of variance (ANOVA) and Design-Expert software (State Ease Inc., Minneapolis, MN, USA) was used to design the experiments and carry out the regression and graphical analysis of the data $[6,7]$.

2.6. Proton Nuclear Magnetic Resonance Spectroscopy $\left({ }^{1} \mathrm{H}\right.$ $N M R)$. Figure 1 shows the ${ }^{1} \mathrm{H}-\mathrm{NMR}$ spectra of the WCO biodiesel that ${ }^{1} \mathrm{H}-\mathrm{NMR}$ was performed for monitoring the transesterification reaction in the form of \% FAME conversion. 


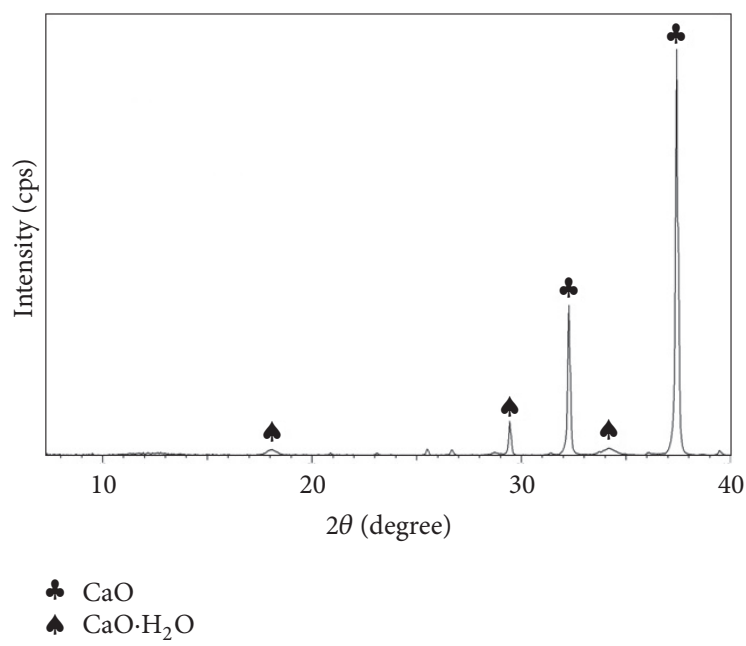

(a)

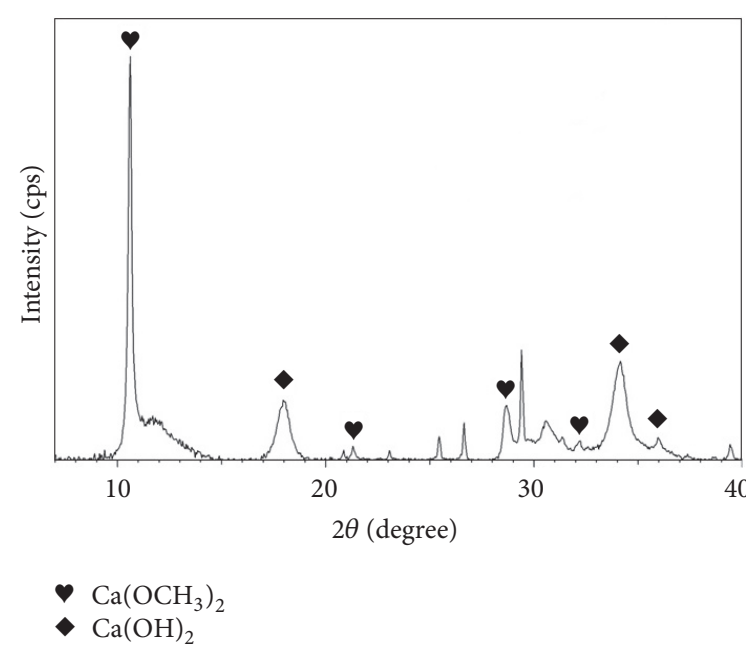

(b)

Figure 2: XRD patterns. (a) Calcined quick lime powder. (b) $\mathrm{Ca}\left(\mathrm{OCH}_{3}\right)_{2}$.

The \% FAME conversion was analyzed following Knothe [10]. Briefly explained, the chemical shift at $3.6 \mathrm{ppm}$ represented the methyl ester protons and at $2.3 \mathrm{ppm}$ represented the methylene protons $\left(\alpha-\mathrm{CH}_{2}\right)$. An equation to calculate the $\%$ FAME conversion is shown in $[9,10]$

$$
C=100 \times\left\{\frac{2 A_{\mathrm{ME}}}{3 A_{\alpha-\mathrm{CH}_{2}}}\right\},
$$

where $C$ is the percentage of FAME conversion, $A_{\mathrm{ME}}$ is the integration value of the protons of the methyl esters and $A_{\alpha-\mathrm{CH}_{2}}$ is the integration value of the methylene protons.

\subsection{Physicochemical Characterization of Produced Biodiesel.} The purified biodiesel obtained from transesterification was tested to evaluate its fuel properties using the recommended standard method: kinetic viscosity at $40^{\circ} \mathrm{C}$ (ASTM D445), density at $15^{\circ} \mathrm{C}$ (EN ISO 3675), acid value (ASTM D 664), water and sediment (ASTM D2709), and fatty acid methyl ester purity (EN 141003). All properties were analyzed in duplicate and reported as the average value.

\section{Results and Discussion}

3.1. Catalyst Characterization. In this study, the XRD results were compared with the standard diffraction pattern in the data base of the International Center of Diffraction Data (ICDD). Figure 2(a) shows the XRD patterns of the calcium oxide $(\mathrm{CaO})$ obtained from the calcined quick lime power. The diffraction peaks at $2 \theta$ of $32.28^{\circ}$ and $37.58^{\circ}$ were attributed to the $\mathrm{CaO}$ (ICDD file number 00-001-1160) and three diffraction peaks at $2 \theta$ of $18.12^{\circ} \mathrm{C}, 28.73^{\circ} \mathrm{C}$, and $34.23^{\circ} \mathrm{C}$ were attributed to calcium oxide hydrate $\left(\mathrm{CaO} \cdot \mathrm{H}_{2} \mathrm{O}\right)$ (ICDD file number 00-002-0969). Figure 2(b) shows the XRD of $\mathrm{Ca}\left(\mathrm{OCH}_{3}\right)_{2}$ catalysts from calcined quick lime powder after reacting with methanol under reflux conditions. The four diffraction peaks that appeared at $2 \theta$ of $10.62^{\circ}, 21.31^{\circ}$,

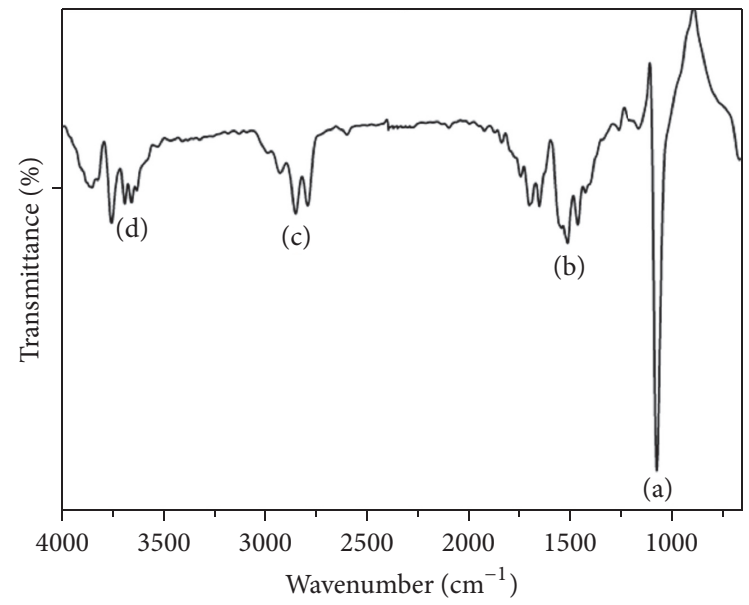

FIgURE 3: ATR-FTIR spectrum of $\mathrm{Ca}\left(\mathrm{OCH}_{3}\right)_{2}$.

28.69 , and $32.24^{\circ}$ were assigned to the characteristic peak of $\mathrm{Ca}\left(\mathrm{OCH}_{3}\right)_{2}$ (ICDD file number 00-031-1574) and ICDD file number 01-070-5492 for $\mathrm{Ca}(\mathrm{OH})_{2}$ [9]. In order to confirm the functional group on the $\mathrm{Ca}\left(\mathrm{OCH}_{3}\right)_{2}$ catalyst, the ATRFTIR spectrum is shown in Figure 3. The distinct peak at $1072.40 . \mathrm{cm}^{-1}$ (a) is assigned to the $-\mathrm{C}-\mathrm{O}$ bond stretching vibration. A series of peaks at $1462.02 \mathrm{~cm}^{-1}$ (b), $2841.10 \mathrm{~cm}^{-1}$ (c), and $3645.40 \mathrm{~cm}^{-1}$ (d) are the $-\mathrm{C}-\mathrm{H}$ bending vibration, $-\mathrm{CH}_{3}$ stretching vibration, and $-\mathrm{OH}$ stretching vibration, respectively.

3.2. Optimization of Reaction Conditions by RSM. RSM was employed to evaluate the relations between the response (\% FAME conversion) and the four reaction variables. The coded and uncoded independent variables for reaction experiment parameter were designed as shown in Table 1 . Thirty experiments were performed in a randomized order. The results 
TABLE 1: Reaction condition variables and levels for CCD.

\begin{tabular}{|c|c|c|c|c|c|c|}
\hline \multirow{2}{*}{ Reaction condition variables } & \multirow{2}{*}{ Symbol code } & \multicolumn{5}{|c|}{ Range and levels } \\
\hline & & -2 & -1 & 0 & +1 & +2 \\
\hline Methanol-to-oil molar ratio & $A$ & 6 & 8 & 10 & 12 & 14 \\
\hline Catalyst concentration (wt\%) & $B$ & 1.5 & 2 & 2.5 & 3 & 3.5 \\
\hline Reaction time (min) & $C$ & 30 & 60 & 90 & 120 & 150 \\
\hline THF in methanol (\% v/v) & $D$ & 4.5 & 6 & 7.5 & 9 & 10.5 \\
\hline
\end{tabular}

TABLE 2: Experimental design with observed and predicted values from transesterification of WCO.

\begin{tabular}{|c|c|c|c|c|c|c|}
\hline Run number & $\begin{array}{c}A: \text { methanol-to-oil } \\
\text { molar ratio }\end{array}$ & $\begin{array}{c}B: \text { catalyst } \\
\text { concentration } \\
(\mathrm{wt} \%)\end{array}$ & $\begin{array}{l}C: \text { reaction time } \\
\qquad(\min )\end{array}$ & $\begin{array}{c}D: \text { THF } \\
\text { concentration } \\
(\mathrm{v} / \mathrm{v} \%)\end{array}$ & $\begin{array}{c}\text { Observed } \\
\text { FAME } \\
(\%)\end{array}$ & $\begin{array}{c}\text { Predicted FAME } \\
(\%)\end{array}$ \\
\hline 1 & $8(-1)$ & $2(-1)$ & $60(-1)$ & $6(-1)$ & 71.17 & 68.98 \\
\hline 2 & $12(+1)$ & $2(-1)$ & $60(-1)$ & $6(-1)$ & 71.43 & 71.99 \\
\hline 3 & $8(-1)$ & $3(+1)$ & $60(-1)$ & $6(-1)$ & 84.85 & 86.73 \\
\hline 4 & $12(+1)$ & $3(+1)$ & $60(-1)$ & $6(-1)$ & 91.94 & 92.26 \\
\hline 5 & $8(-1)$ & $2(-1)$ & $120(+1)$ & $6(-1)$ & 73.83 & 73.79 \\
\hline 6 & $12(+1)$ & $2(-1)$ & $120(+1)$ & $6(-1)$ & 78.71 & 77.14 \\
\hline 7 & $8(-1)$ & $3(+1)$ & $120(+1)$ & $6(-1)$ & 93.25 & 94.02 \\
\hline 8 & $12(+1)$ & $3(+1)$ & $120(+1)$ & $6(-1)$ & 95.87 & 99.88 \\
\hline 9 & $8(-1)$ & $2(-1)$ & $60(-1)$ & $9(+1)$ & 83.44 & 80.06 \\
\hline 10 & $12(+1)$ & $2(-1)$ & $60(-1)$ & $9(+1)$ & 84.3 & 81.59 \\
\hline 11 & $8(-1)$ & $3(+1)$ & $60(-1)$ & $9(+1)$ & 89.76 & 89.38 \\
\hline 12 & $12(+1)$ & $3(+1)$ & $60(-1)$ & $9(+1)$ & 92.74 & 93.41 \\
\hline 13 & $8(-1)$ & $2(-1)$ & $120(+1)$ & $9(+1)$ & 84.56 & 82.30 \\
\hline 14 & $12(+1)$ & $2(-1)$ & $120(+1)$ & $9(+1)$ & 85.4 & 84.16 \\
\hline 15 & $8(-1)$ & $3(+1)$ & $120(+1)$ & $9(+1)$ & 94.02 & 94.09 \\
\hline 16 & $12(+1)$ & $3(+1)$ & $120(+1)$ & $9(+1)$ & 98.22 & 98.46 \\
\hline 17 & $6(-2)$ & $2.5(0)$ & $90(0)$ & $7.5(0)$ & 81.03 & 83.15 \\
\hline 18 & $14(+2)$ & $2.5(0)$ & $90(0)$ & $7.5(0)$ & 91.34 & 90.54 \\
\hline 19 & $10(0)$ & $1.5(-2)$ & $90(0)$ & $7.5(0)$ & 50.57 & 56.33 \\
\hline 20 & $10(0)$ & $3.5(+2)$ & $90(0)$ & $7.5(0)$ & 92.83 & 88.38 \\
\hline 21 & $10(0)$ & $2.5(0)$ & $30(-2)$ & $7.5(0)$ & 81.72 & 83.68 \\
\hline 22 & $10(0)$ & $2.5(0)$ & $150(+2)$ & $7.5(0)$ & 94.19 & 93.54 \\
\hline 23 & $10(0)$ & $2.5(0)$ & $90(0)$ & $4.5(-2)$ & 91.94 & 89.41 \\
\hline 24 & $10(0)$ & $2.5(0)$ & $90(0)$ & $10.5(+2)$ & 95.24 & 99.08 \\
\hline 25 & $10(0)$ & $2.5(0)$ & $90(0)$ & $7.5(0)$ & 97.75 & 95.02 \\
\hline 26 & $10(0)$ & $2.5(0)$ & $90(0)$ & $7.5(0)$ & 95.61 & 95.02 \\
\hline 27 & 10 & 2.5 & 90 & 7.5 & 93.33 & 95.02 \\
\hline 28 & 10 & 2.5 & 90 & 7.5 & 96.1 & 95.02 \\
\hline 29 & 10 & 2.5 & 90 & 7.5 & 93.16 & 95.02 \\
\hline 30 & 10 & 2.5 & 90 & 7.5 & 94.19 & 95.02 \\
\hline
\end{tabular}

for each point base on the CCD experimental plans are shown in Table 2. The response obtained from the regression analysis was correlated with the four independent variables using second-order polynomial equation (see (3)). The \% FAME conversion obtained at the design points of different reaction conditions is shown in Table 2 . The observed values varied between $50.57 \%$ at $1.50 \%$ catalyst concentration, $10: 1$ methanol-to-oil molar ratio, $90 \mathrm{~min}$ reaction time, and $7.5 \%$ THF in methanol concentration and $98.22 \%$ at $3 \%$ catalyst concentration, 12:1 methanol-to-oil molar ratio, $120 \mathrm{~min}$ reaction time, and 9\% THF in methanol concentration.

The Design-Expert software was used to determine and evaluate the coefficients of the full regression model equation and their statistical significance. The quadratic regression model used to predict the \% FAME conversion is shown in

$$
\begin{aligned}
Y= & -231.274+10.387 A+140.443 B+0.393 C \\
& +12.464 D+0.628 A B+0.001 A C-0.124 A D \\
& +0.041 B C-2.811 B D-0.014 C D-0.511 A^{2} \\
& -22.666 B^{2}-0.002 C^{2}-0.086 D^{2}
\end{aligned}
$$

where $Y$ is the response variable of \% FAME conversion and $A, B, C$, and $D$ are the actual values of the predicted methanolto-oil molar ratio, catalyst concentration, reaction time, and THF in methanol concentration, respectively. 
TABLE 3: ANOVA for the response surface quadratic model.

\begin{tabular}{|c|c|c|c|c|c|c|}
\hline Source of variation & Sum of squares & $\mathrm{df}^{\mathrm{a}}$ & Mean square & $F$-value & $P$ value $^{\mathrm{b}}$ & Significant at $5 \%$ level \\
\hline Model & 2957.24 & 14 & 211.23 & 20.65 & $<0.0001$ & Yes \\
\hline$A$ & 81.96 & 1 & 81.96 & 8.01 & 0.0127 & Yes \\
\hline$B$ & 1541.28 & 1 & 1541.28 & 150.69 & $<0.0001$ & Yes \\
\hline C & 145.88 & 1 & 145.88 & 14.26 & 0.0018 & Yes \\
\hline$D$ & 140.12 & 1 & 140.12 & 13.70 & 0.0021 & Yes \\
\hline$A B$ & 6.31 & 1 & 6.31 & 0.62 & 0.4443 & No \\
\hline$A C$ & 0.11 & 1 & 0.11 & 0.011 & 0.9174 & No \\
\hline$A D$ & 2.23 & 1 & 2.23 & 0.22 & 0.6474 & No \\
\hline$B C$ & 6.14 & 1 & 6.14 & 0.60 & 0.4506 & No \\
\hline$B D$ & 71.11 & 1 & 71.11 & 6.95 & 0.0187 & Yes \\
\hline$C D$ & 6.64 & 1 & 6.64 & 0.65 & 0.4329 & No \\
\hline$A^{2}$ & 114.74 & 1 & 114.74 & 11.22 & 0.0044 & Yes \\
\hline$B^{2}$ & 880.73 & 1 & 880.73 & 86.11 & $<0.0001$ & Yes \\
\hline$C^{2}$ & 70.46 & 1 & 70.46 & 6.89 & 0.0191 & Yes \\
\hline$D^{2}$ & 1.03 & 1 & 1.03 & 0.10 & 0.7550 & No \\
\hline Residual & 153.42 & 15 & 10.23 & & & \\
\hline Lack of fit & 137.45 & 10 & 13.74 & 4.30 & 0.0604 & No \\
\hline Pure error & 15.97 & 5 & 3.19 & & & \\
\hline Cor total & 3110.66 & 29 & & & & \\
\hline
\end{tabular}

${ }^{\mathrm{a}} \mathrm{df}=$ degree of freedom; ${ }^{\mathrm{b}} \mathrm{P}>0.05$ is not significantly different at the $5 \%$ level.

The obtained data were evaluated using analysis of variance (ANOVA) for fitting a quadratic response surface model by the least squares method and to assess the quality of the fit. The significance of each coefficient parameter was determined by probability value ( $P$ value) as shown in Table 3. At the $95 \%$ confidence level, $F_{\text {model }}=20.65$, the $P$ value less than 0.05 clearly indicated that the high significance of the fitted model and is showing the reliability of the regression model for predicting the \% FAME conversion $[6,11]$. Furthermore, the variables of $A, B, C, D, B D, A^{2}, B^{2}$, and $C^{2}$ were found to be significant at the $95 \%$ confidence level according to the computed high $F$-value and the $P$ values at the $5 \%$ level.

Thus, these statistical tests indicated that the selected model is satisfactory for predicting the \% FAME conversion within the range of the experiment variables studies. The $P$ value of the lack of fit was 0.0604 , which reveals that it was not significant. Therefore, the number of experiments was sufficient to study the effect of the variable factors on $\%$ FAME conversion $[6,12]$. The suitability of the model was tested using the determination coefficient $\left(R^{2}\right)$. The high value of $R^{2}$ (0.9507) indicates that the fitted model can be used to predict reasonably precise outcome [6].

Figure 4 represents the actual results obtained from the experiments versus the predicted data by empirical model. The values of the adjusted determination coefficient $\left(R^{2}{ }_{\text {adj }}\right)$ and the determination coefficient $\left(R^{2}\right)$ were 0.9046 and 0.9507 , respectively. The high value of both coefficients justifies an excellent correlation between the independent variables and supports a high significance of the model. Meanwhile, the coefficient of variation was $3.66 \%$. The relatively low value of the coefficient of variation reveals better reliability for this fitted model $[6,13]$.

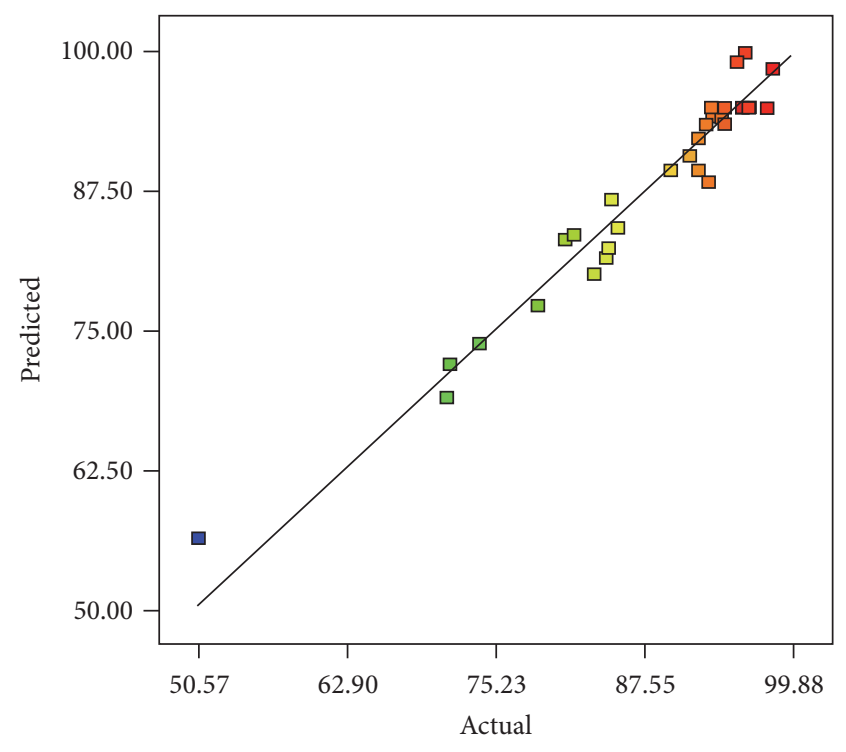

Figure 4: Plot of predicted \% FAME conversion versus actual \% FAME conversion.

The effects of the process variables on the FAME conversion were studied by plotting three-dimensional surface curves against any two independent variables while keeping the other variables at their central (0) level [14]. The 3D curves of the response from the effect of independent variables are shown in Figures 5(a)-5(f).

Figure 5(a) illustrates the effect of catalyst concentration and THF in methanol concentration on the \% FAME conversion at $90 \mathrm{~min}$ reaction time and a 10:1 methanolto-oil molar ratio. The result reveals that the \% FAME 


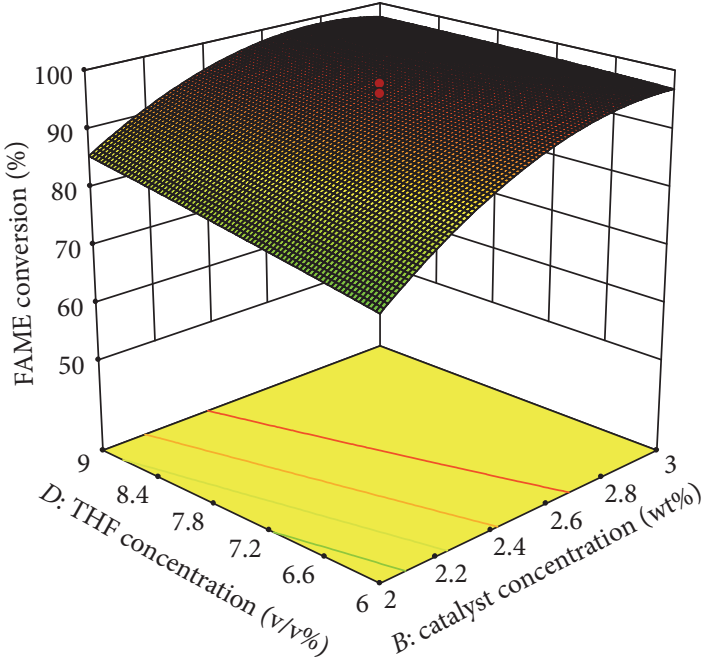

(a)

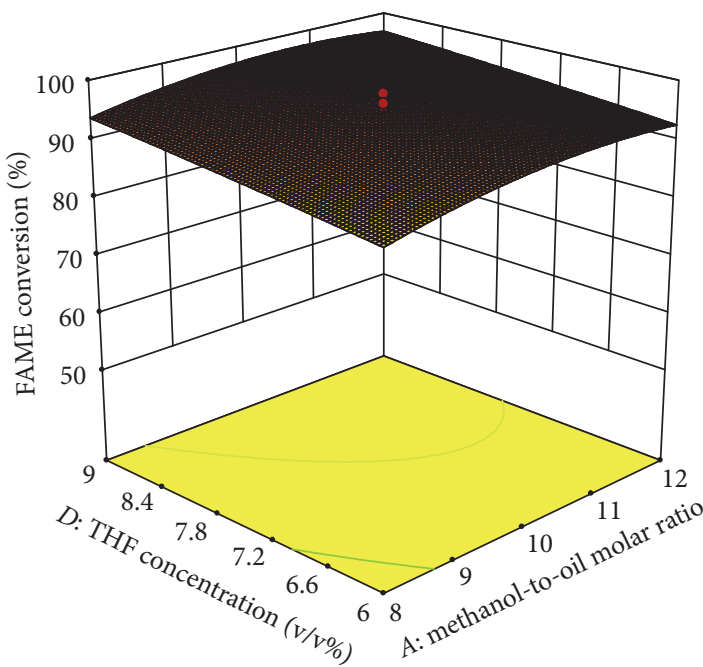

(c)

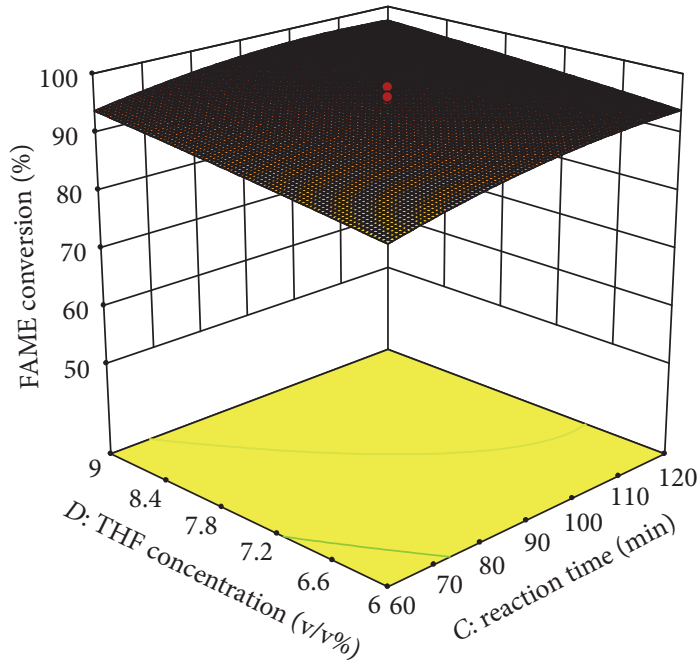

(e)

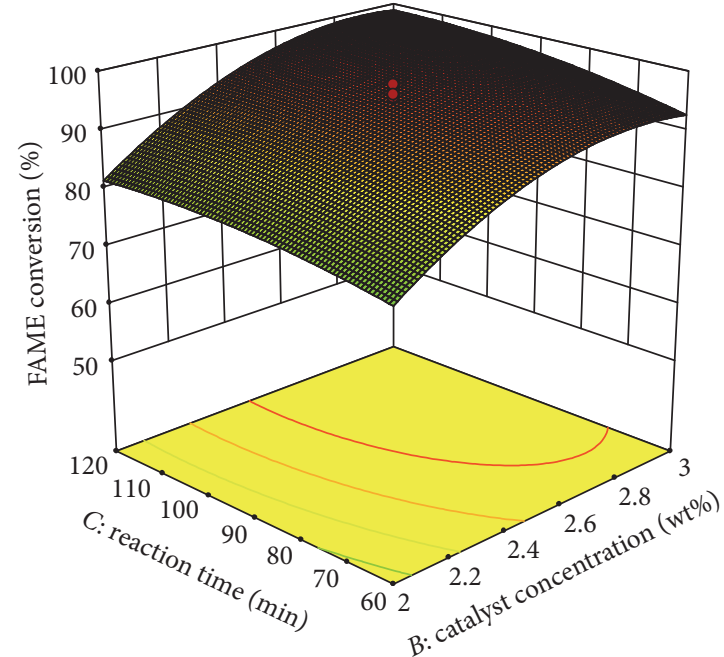

(b)

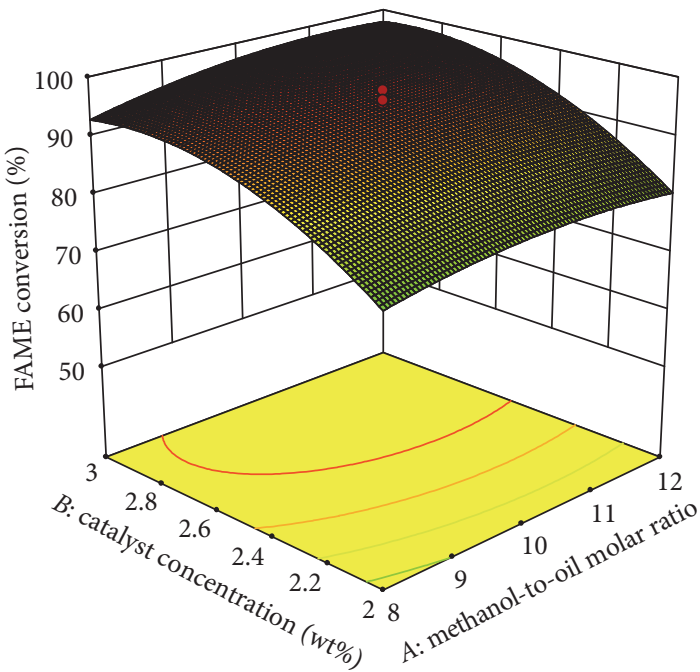

(d)

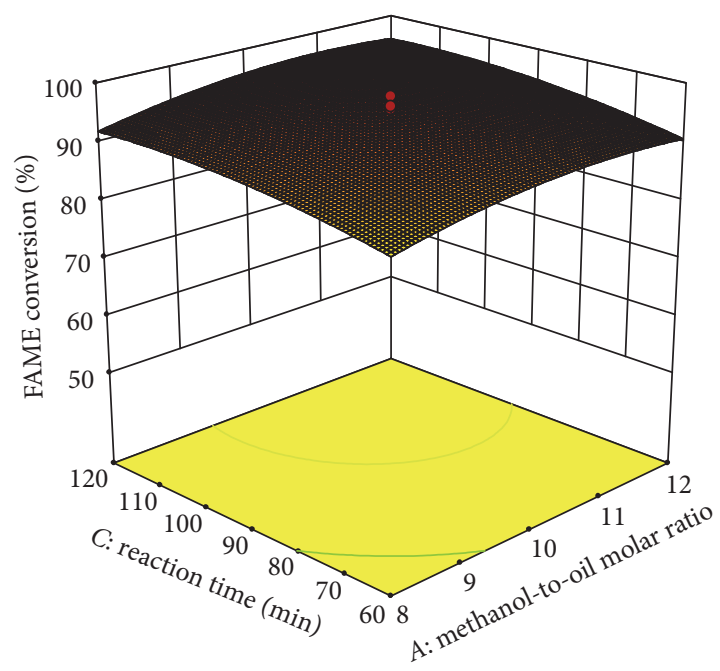

(f)

FIGURE 5: Response surface plots elucidating the effects of (a) THF in methanol concentration and catalyst concentration; (b) reaction time and catalyst concentration; (c) THF in methanol concentration and methanol-to-oil molar ratio; (d) catalyst concentration and methanolto-oil molar ratio; (e) THF in methanol concentration and reaction time; and (f) reaction time and methanol-to-oil molar ratio. 
TABLE 4: Numerical optimization of the reaction conditions using RSM.

\begin{tabular}{lcccccc}
\hline Solution number & $A$ & $B$ & $C$ & $D$ & \% FAME conversion & Desirability \\
\hline 1 & 11.60 & 2.83 & 100.14 & 8.65 & 99.43 & 0.999 \\
2 & 11.61 & 2.82 & 100.14 & 8.65 & 99.42 & 0.998 \\
3 & 11.61 & 2.83 & 100.14 & 8.63 & 99.42 & 0.998 \\
4 & 11.61 & 2.82 & 100.14 & 8.64 & 99.42 & 0.997 \\
5 & 11.58 & 2.83 & 100.14 & 8.34 & 99.39 & 0.974 \\
\hline
\end{tabular}

TABLE 5: Optimum reaction conditions and validation test.

\begin{tabular}{lcccccrr}
\hline Exp. number & $A$ & $B$ & $C$ & $D$ & Observed FAME (\%) & Predicted FAME (\%) & Error \\
\hline 1 & 11.60 & 2.83 & 100.14 & 8.65 & 98.70 & 99.43 & 0.73 \\
2 & 11.60 & 2.83 & 100.14 & 8.65 & 99.57 & 99.43 \\
3 & 11.60 & 2.83 & 100.14 & 8.65 & 99.12 & 99.43 \\
\hline
\end{tabular}

TABLE 6: Optimum conditions using $\mathrm{Ca}\left(\mathrm{OCH}_{3}\right)_{2}$ with and without THF as cosolvent for WCO biodiesel production.

\begin{tabular}{lccccc}
\hline \multirow{2}{*}{$\begin{array}{l}\text { Method } \\
\text { Temperature }\left({ }^{\circ} \mathrm{C}\right)\end{array}$} & $\begin{array}{c}\text { Methanol-to-oil molar ratio } \\
\text { Catalyst (wt\%) }\end{array}$ & $\begin{array}{c}\mathrm{Ca}\left(\mathrm{OCH}_{3}\right)_{2} \\
\text { Came (min) }\end{array}$ & $\begin{array}{c}\text { FAME } \\
\text { Conversion }\end{array}$ \\
\hline Pithourity $(\%)$ \\
With THF & $65^{\circ} \mathrm{C}$ & $12: 1$ & 3 & 180 & 99.06 \\
\hline
\end{tabular}

conversion increases with increasing catalyst concentration and THF concentration. For the amount of catalyst, there is a significant positive effect on the transesterification of vegetable oil to methyl ester due to the number of active sites available for the reaction [15]. The 3D response curve indicates that the interaction of catalyst concentration and THF concentration is significant in the reaction.

Figure 5(b) exhibits the effect of the catalyst concentration and reaction time at 10:1 methanol-to-oil molar ratio and 7.5\% THF concentration. The \% FAME conversion increases with increasing catalyst concentration and reaction time. Then, there is a slight decrease when the reaction period is too long due to the influence of the reversible reaction in transesterification [16]. The $3 \mathrm{D}$ response curve reveals that there is no significant interaction effect between the catalyst concentration and reaction time on the \% FAME conversion.

Figure 5(c) shows the effect of the methanol-to-oil molar ratio and THF concentration at a $90 \mathrm{~min}$ reaction time and $2.5 \%$ catalyst concentration. The \% FAME conversion increases with the increasing methanol-to-oil molar ratio and THF concentration. In general, a high molar ratio results in a higher rate of methyl ester formation and ensures completion of the reaction. However, overloading of methanol would inactivate the catalyst and reversed the reaction since transesterification is a reversible reaction [17]. The $3 \mathrm{D}$ response curve under this condition indicates no significant interaction effect between methanol-to-oil molar ratio and THF concentration on the \% FAME conversion.

Figures 5(d)-5(f) illustrate the effect of the methanolto-oil molar ratio and catalyst concentration, the effect of reaction time and THF concentration, and the effect of methanol-to-oil-molar ratio and reaction time, respectively. The interaction effect of two independent variables was studied by keeping the other variables at their central (0) level. The results demonstrate that the \% FAME conversion increased with an increase in all variables. The $3 \mathrm{D}$ response curves in Figures 5(d)-5(f) show no significant interaction effect of the methanol-to-oil molar ratio and catalyst concentration, reaction time, and THF concentration including the methanolto-oil molar ratio and reaction time on \% FAME conversion.

The optimal transesterification conditions were predicted by applying numerical optimization with the Design-Expert software using RSM. The results are shown in Table 4. The optimal conditions for the maximum value of $\%$ FAME conversion are as follows: 11.60:1 methanol-to-oil molar ratio, $2.83 \mathrm{wt} \%$ of catalyst, $100.14 \mathrm{~min}$ of reaction time, and $8.65 \%$ of THF in methanol concentration. Experiments were also conducted to verify the accuracy of the predicted model, and the experiment at the selected optimal conditions was performed with three replicates to confirm the experimental results as shown in Table 5. The predicted conversion value of 99.43 was approximately equal to the average observed value of 99.13. Therefore, the experimental (obtained) value showed acceptable agreement with the predicted values. The errors values between the predicted and the observed results were less than 1\% FAME conversion indicating that the regression model was satisfactory.

\subsection{Comparison of WCO Biodiesel Production Using} $\mathrm{Ca}\left(\mathrm{OCH}_{3}\right)_{2}$ and without THF as Cosolvent. In the authors' previous work (Chumuang and Punsuvon, 2016) [18], the production of WCO biodiesel using $\mathrm{Ca}\left(\mathrm{OCH}_{3}\right)_{2}$ without THF as cosolvent was studied and the results of the optimum conditions were compared with THF as a cosolvent as shown in Table 6.

For production without THF as cosolvent, the optimum conditions were 12:1 methanol-to-oil-molar ratio, 3\% $\mathrm{Ca}\left(\mathrm{OCH}_{3}\right)_{2}$ catalyst concentration, 180 min reaction time, 
TABLE 7: Optimum condition of difference catalyst assisted with THF as cosolvent for biodiesel production.

\begin{tabular}{lcccccc}
\hline Method & $\begin{array}{c}\text { Temperature } \\
\left({ }^{\circ} \mathrm{C}\right)\end{array}$ & $\begin{array}{c}\text { Methanol-to-oil } \\
\text { molar ratio }\end{array}$ & $\begin{array}{c}\text { Amount of } \\
\text { catalyst (wt\%) }\end{array}$ & $\begin{array}{c}\text { THF in } \\
\text { methanol } \\
(\% \mathrm{v} / \mathrm{v})\end{array}$ & $\begin{array}{c}\text { Time } \\
(\mathrm{min})\end{array}$ & $\begin{array}{c}\text { FAME } \\
\text { Purity }(\%)\end{array}$ \\
\hline Present work & $65^{\circ} \mathrm{C}$ & $11.60: 1$ & 2.83 & 8.65 & 100.14 \\
Reference work & $65^{\circ} \mathrm{C}$ & $12: 1$ & 5.00 & 10.00 & 97.13 \\
\hline
\end{tabular}

TABLE 8: Biodiesel properties.

\begin{tabular}{lccc}
\hline Parameters & Testing method & Specification & WCO biodiesel \\
\hline Viscosity at $40^{\circ} \mathrm{C}(\mathrm{cSt})$ & ASTM D 445 & $1.9-6.0$ & 4.78 \\
Density at $15^{\circ} \mathrm{C}\left(\mathrm{g} / \mathrm{cm}^{3}\right)$ & EN ISO 3675 & $0.86-0.90$ & 0.89 \\
Acid value $(\mathrm{mg} \mathrm{KOH} / \mathrm{g})$ & ASTM D 664 & 0.80 max & 0.53 \\
Water and sediment $(\mathrm{v} \%)$ & ASTM D 2709 & 0.05 max & $<0.05$ \\
Methyl ester purity $(\mathrm{wt} \%)$ & EN 14103 & $\geq 96.5$ & 97.13 \\
\hline
\end{tabular}

and $65^{\circ} \mathrm{C}$ reaction temperature resulting in $99.06 \%$ FAME conversion and $97.00 \%$ FAME purity. On the other hand biodiesel production with THF as a cosolvent was able to decrease the methanol-to-oil molar ratio (12:1 to $11.60: 1)$, $\mathrm{Ca}\left(\mathrm{OCH}_{3}\right)_{2}$ catalyst concentration (3 to $2.83 \mathrm{wt} \%$ ), and reaction time (180 to $100.14 \mathrm{~min}$ ) while still maintaining the $\%$ FAME conversion and \% FAME purity at nearly the same levels. The results indicated that THF can accelerate the catalyzed reaction by improving the mixing between the methanol, WCO, and $\mathrm{Ca}\left(\mathrm{OCH}_{3}\right)_{2}$ catalyst. Thus, our discovery can solve the problem of phase separation between hydrophilic methanol, hydrophobic oil, and a solid catalyst that is generally accepted to be major problem in using a heterogeneous catalyst in biodiesel production [5].

3.4. Comparison of Biodiesel Production between $\mathrm{Ca}\left(\mathrm{OCH}_{3}\right)_{2}$ Catalyst Assisted with THF and $\mathrm{CaO}$ Catalyst Assisted with THF as Cosolvent. In the work [5], the transesterification for palm oil biodiesel production was studied using $\mathrm{CaO}$ catalyst assisted with THF as cosolvent. The optimum condition between the reference work and our present work is shown in Table 7.

For the reference work, the optimum conditions were $65^{\circ} \mathrm{C}$ reaction temperature, $12: 1$ methanol-to-oil molar ratio, $5 \%$ wt $\mathrm{CaO}$ catalyst concentration, $10 \% \mathrm{v} / \mathrm{v}$ THF in methanol concentration, and $90 \mathrm{~min}$ reaction time resulting in $98.5 \pm$ $1.5 \%$ FAME purity. On the other hand, our present work using $\mathrm{Ca}\left(\mathrm{OCH}_{3}\right)_{2}$ assisted with THF as cosolvent was able to decrease the methanol-to-oil molar ratio $(12: 1$ to $11.60: 1)$, amount of catalyst (5 to $2.83 \% \mathrm{wt}$ ), and THF in methanol concentration (10 to $8.65 \% \mathrm{v} / \mathrm{v}$ ), while still maintaining the $\%$ FAME purity at nearly the same levels (97.13 and 98.5 $\pm 1.5 \%$ ) on the same reaction temperature $\left(65^{\circ} \mathrm{C}\right)$. The reaction time was only one variable of our present work that had longer time than the reference work (100.14 and $90 \mathrm{~min})$. Thus, the result indicated that both $\mathrm{Ca}\left(\mathrm{OCH}_{3}\right)_{2}$ and $\mathrm{CaO}$ assisted with THF as cosolvent could produce both biodiesels with high purity of FAME but $\mathrm{Ca}\left(\mathrm{OCH}_{3}\right)_{2}$ catalyst was better than $\mathrm{CaO}$ catalyst in terms of catalyst concentration, methanol-to-oil molar ratio, and THF in methanol concentration except reaction time.

3.5. Biodiesel Properties. The biodiesel properties were tested following the biodiesel standards of the USA (ASTM) and Europe (EN), as exhibited in Table 8.

While the result on viscosity result (at $40^{\circ} \mathrm{C}$ ) of this WCO biodiesel is slightly lower $(4.78 \mathrm{cst})$, the value is still within the range of ASTM D445 (1.9-6.0 cst). The density of WCO biodiesel falls in the range of the EN ISO 3675 specifications $\left(0.86-0.90 \mathrm{~g} / \mathrm{cm}^{2}\right)$. The acid value of this biodiesel was also found to be $0.53 \mathrm{mg} \mathrm{KOH} / \mathrm{g}$ which is within the range of ASTM D664 specifications ( $\leq 0.80 \mathrm{mg} \mathrm{KOH} / \mathrm{g})$. The amounts of water and sediment produced in the biodiesel were less than $0.05 \%$ by volume which is in the range of the ASTM D2709 specification $(\leq 0.05 \% \mathrm{v})$. The methyl ester purity was determined using the GC method and it was found to be $97.13 \%$ which falls in the range of the EN 14103 specification $(\geq 96.5 \%)$.

3.6. Reusability of the Catalyst. One of the most important advantages of employing a heterogeneous catalyst is its reusability. $\mathrm{Ca}\left(\mathrm{OCH}_{3}\right)_{2}$ was separated from the reaction mixture by centrifugation followed by washing with hexane and methanol to remove the adsorbed stains. Then, $\mathrm{Ca}\left(\mathrm{OCH}_{3}\right)_{2}$ was collected by filtration and finally dried overnight at $105^{\circ} \mathrm{C}$ in an oven. The dried catalyst was further reused under the obtained optimal transesterification condition for biodiesel production. Figure 6 shows the relationship between the number of reused times and the \% FAME conversion and indicates that a high \% FAME (higher than 80\%) was still obtained with five times of reuse.

\section{Conclusion}

RSM was applied to the transesterification reaction between WCO and methanol using a $\mathrm{Ca}\left(\mathrm{OCH}_{3}\right)_{2}$ catalyst assisted with THF as a cosolvent. The significant merit of THF as cosolvent is the short reaction time, low concentration of 


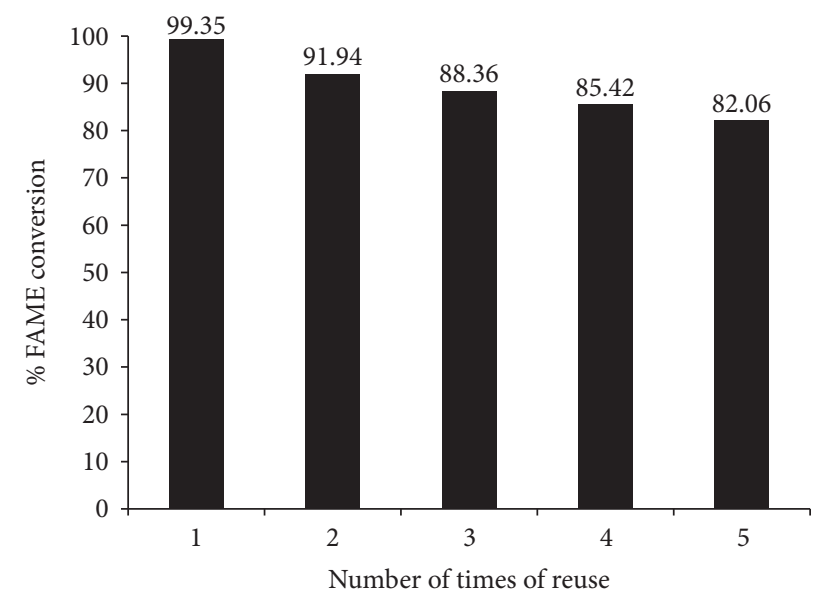

Figure 6: $\mathrm{Ca}\left(\mathrm{OCH}_{3}\right)_{2}$ catalyst reusability testing.

the catalyst, and the low value of the methanol-to-oil-molar ratio compared to the reaction without THF as a cosolvent. The synthesized $\mathrm{Ca}\left(\mathrm{OCH}_{3}\right)_{2}$ provides high catalytic activity for transesterification in terms of \% FAME conversion and \% FAME purity and reusability. These results indicate that $\mathrm{Ca}\left(\mathrm{OCH}_{3}\right)_{2}$ and THF as a cosolvent are both capable of improving the transesterification of WCO for biodiesel production.

\section{Conflicts of Interest}

The authors declare that there are no conflicts of interest regarding the publication of this paper.

\section{Acknowledgments}

This work was supported by the Higher Education Research Promotion and National Research University Project of Thailand, Office of the Higher Education Commission, and the Department of Chemistry, Faculty of Science, Kasetsart University, Bangkok, Thailand.

\section{References}

[1] Z. Helwani, M. R. Othman, N. Aziz, W. J. N. Fernando, and J. Kim, "Technologies for production of biodiesel focusing on green catalytic techniques: a review," Fuel Processing Technology, vol. 90, no. 12, pp. 1502-1514, 2009.

[2] R. Jothiramalingam and M. K. Wang, "Review of recent developments in solid acid, base, and enzyme catalysts (heterogeneous) for biodiesel production via transesterification," Industrial and Engineering Chemistry Research, vol. 48, no. 13, pp. 6162-6172, 2009.

[3] M. K. Lam and K. T. Lee, "Accelerating transesterification reaction with biodiesel as co-solvent: a case study for solid acid sulfated tin oxide catalyst," Fuel, vol. 89, no. 12, pp. 3866-3870, 2010.

[4] D. G. B. Boocock, S. K. Konar, V. Mao, and H. Sidi, "Fast onephase oil-rich processes for the preparation of vegetable oil methyl esters," Biomass and Bioenergy, vol. 11, no. 1, pp. 43-50, 1996.
[5] W. Roschat, T. Siritanon, T. Kaewpuang, B. Yoosuk, and V. Promarak, "Economical and green biodiesel production process using river snail shells-derived heterogeneous catalyst and cosolvent method," Bioresource Technology, vol. 209, pp. 343-350, 2016.

[6] W. Suwanthai, V. Punsuvon, and P. Vaithanomsat, "Optimization of biodiesel production from a calcium methoxide catalyst using a statistical model," Korean Journal of Chemical Engineering, vol. 33, no. 1, pp. 90-98, 2016.

[7] W. Suwanthai and V. Punsuvon, "Optimization of transesterification reaction for biodiesel production from refined palm oil using calcined quick lime catalyst," Asian Journal of Chemistry, vol. 28, no. 2, pp. 423-428, 2016.

[8] S. Gryglewicz, "Rapeseed oil methyl esters preparation using heterogeneous catalysts," Bioresource Technology, vol. 70, no. 3, pp. 249-253, 1999.

[9] N. Chumuang and V. Punsuvon, "Application of calcium methoxide as solid base catalyst for biodiesel production from waste cooking oil," Key Engineering Materials, vol. 723, pp. 594598, 1999.

[10] G. Knothe, "Analyzing biodiesel: standards and other methods," Journal of the American Oil Chemists' Society, vol. 83, no. 10, pp. 823-833, 2006.

[11] K. T. Lee, A. M. Mohtar, N. F. Zainudin, S. Bhatia, and A. R. Mohamed, "Optimum conditions for preparation of flue gas desulfurization absorbent from rice husk ash," Fuel, vol. 84, no. 2-3, pp. 143-151, 2005.

[12] D. C. Montgomery, Design and Analysis of Experimentss, Wiley, New York, NY, USA, 5th edition, 2001.

[13] X. Yuan, J. Liu, G. Zeng, J. Shi, J. Tong, and G. Huang, "Optimization of conversion of waste rapeseed oil with high FFA to biodiesel using response surface methodology," Renewable Energy, vol. 33, no. 7, pp. 1678-1684, 2008.

[14] D. O. Onukwuli, L. N. Emembolu, C. N. Ude, S. O. Aliozo, and M. C. Menkiti, "Optimization of biodiesel production from refined cotton seed oil and its characterization," Egyptian Journal of Petroleum, vol. 26, no. 1, pp. 103-110, 2016.

[15] G. Arzamendi, I. Campo, E. Arguinarena, M. Sanchez, M. Montes, and L. M. Gandia, "Synthesis of biodiesel with heterogeneous $\mathrm{NaOH} /$ alumina catalysts: comparison with homogeneous $\mathrm{NaOH}$," Chemical Engineering Journal, vol. 134, pp. 123130, 2007.

[16] C. Samart, P. Sreetongkittikul, and C. Sookman, "Heterogeneous catalysis of transesterification of soybean oil using KI/mesoporous silica," Fuel Processing Technology, vol. 90, no. 7-8, pp. 922-925, 2009.

[17] W. N. N. Wan Omar and N. A. Saidina Amin, "Optimization of heterogeneous biodiesel production from waste cooking palm oil via response surface methodology," Biomass and Bioenergy, vol. 35, no. 3, pp. 1329-1338, 2011.

[18] N. Chumuang and V. Punsuvon, "Synthesis of calcium methoxide for using as catalyst in biodiesel production from waste cooking oil," in Proceedings of the Pure and Applied Chemistry International Conference (PACCON '16), pp. 242-247, 2016. 

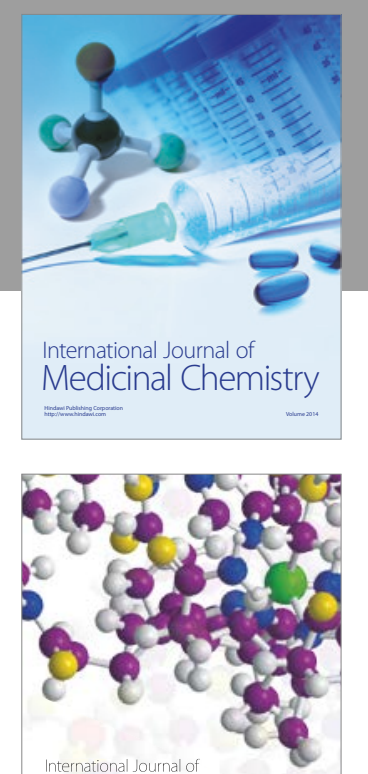

Carbohydrate Chemistry

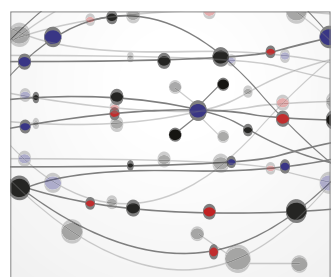

The Scientific World Journal
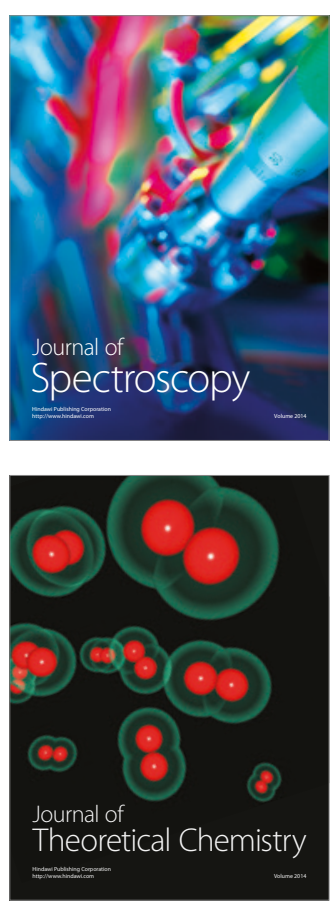
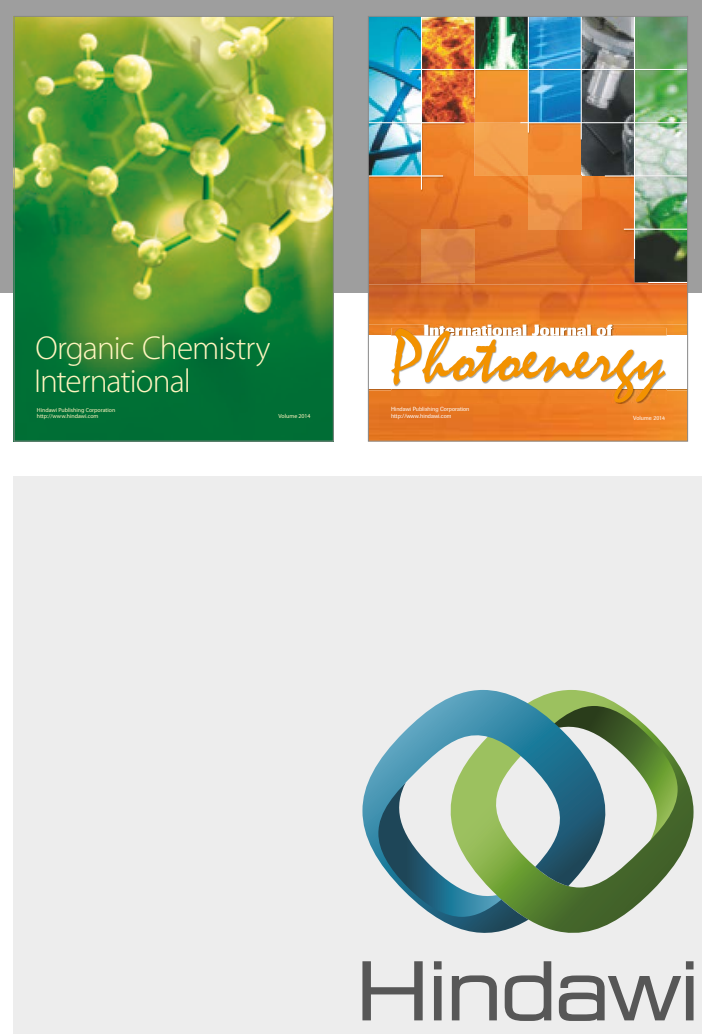

Submit your manuscripts at

https://www.hindawi.com

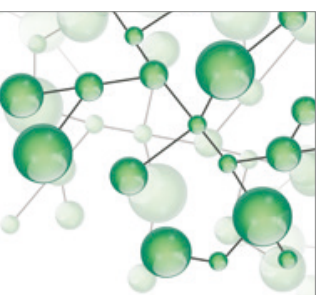

International Journal of

Inorganic Chemistry

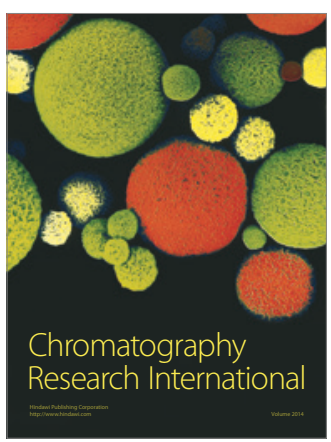

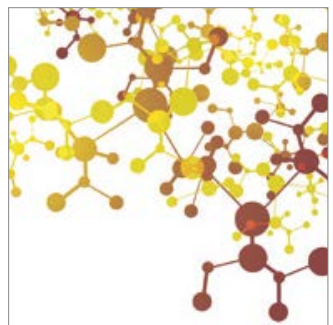

Applied Chemistry
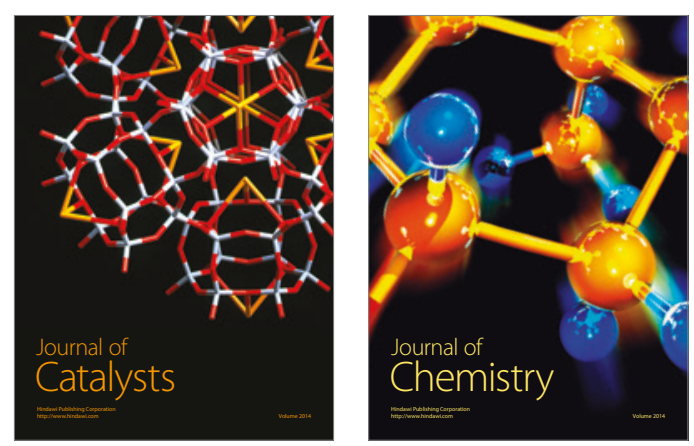
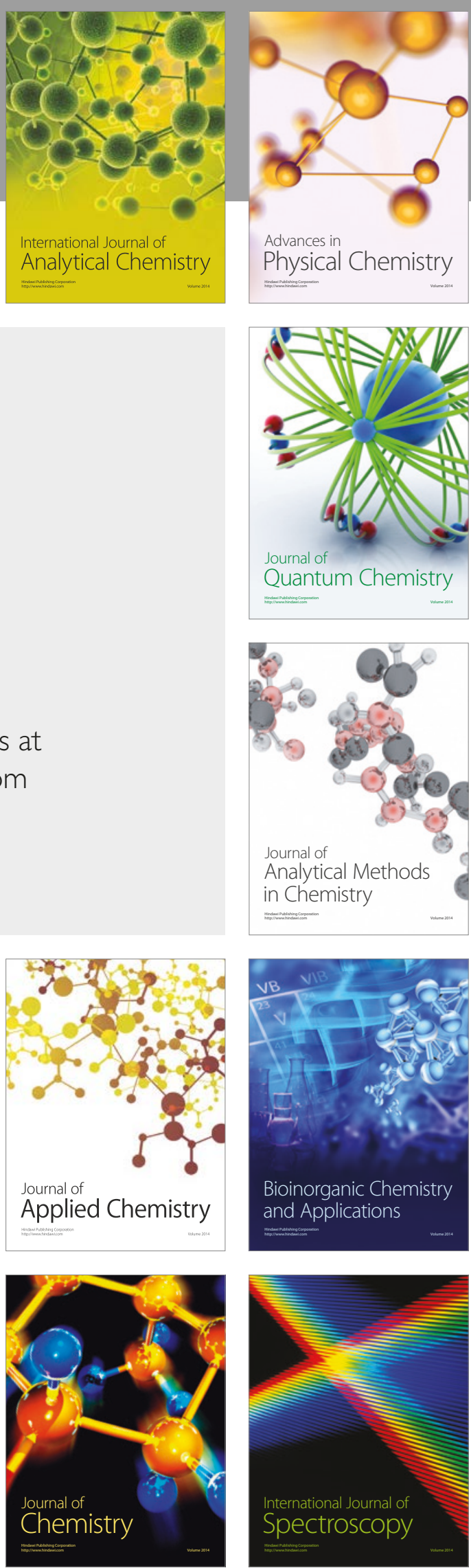